\title{
Correlations of non-exercise activity thermogenesis to metabolic parameters in Japanese patients with type 2 diabetes
}

Hidetaka Hamasaki ${ }^{1,2}$, Hidekatsu Yanai ${ }^{*}$, Shuichi Mishima ${ }^{1}$, Tomoka Mineyama', Ritsuko Yamamoto-Honda ${ }^{3,6}$, Masafumi Kakei ${ }^{2,4}$, Osamu Ezaki ${ }^{3,5}$ and Mitsuhiko Noda ${ }^{3,6}$

\begin{abstract}
Background: Non-exercise activity thermogenesis (NEAT) is the energy expenditure due to physical activities besides active sports-like exercise and resistance training in daily life.

Methods: We studied 45 subjects ( 22 women and 23 men) with type 2 diabetes who did not take any hypoglycemic, anti-hypertensive, or cholesterol-lowering agents and asked them about physical activity concerned with NEAT using an original questionnaire modified from a compendium of physical activities. We studied the association of the NEAT score to body weight, waist circumference, blood pressure, glucose and lipid metabolism, and arterial stiffness.
\end{abstract}

Results: The NEAT score was negatively correlated with serum insulin levels $(r=-0.42, P<0.05)$ in all subjects. The NEAT score was also negatively correlated with waist circumference $(r=-0.509, P<0.05)$ and positively correlated with high-density lipoprotein-cholesterol levels $(r=0.494, P<0.05)$ in women, and negatively associated with serum insulin levels $(r=-0.732, p<0.005)$, systolic $(r=-0.482, P<0.05)$ and diastolic blood pressure $(r=-0.538$, $P<0.05)$ in patients with abdominal obesity. Furthermore, the NEAT score was negatively associated with pulse wave velocity $(r=-0.719, P<0.005)$ in smokers.

Conclusion: The study demonstrated that NEAT is associated with amelioration in insulin sensitivity, waist circumference, high-density lipoprotein-cholesterol, blood pressure and the marker for atherosclerosis in patients with type 2 diabetes.

Keywords: Atherosclerosis, Insulin, Non-exercise activity thermogenesis, Obesity, Type 2 diabetes

\section{Background}

Non-exercise activity thermogenesis (NEAT) is the energy expenditure due to physical activities besides active sports-like exercise and resistance training [1]. It includes various activities in daily life such as going to work, attending school, singing, dancing, washing clothes and cleaning floors [1].

Greater prevalence of cardiovascular diseases (CVD) risk factors in urban or suburban residents is explained by low physical activity [2,3], and a sedentary lifestyle is a major cardiovascular risk factor [4].

\footnotetext{
* Correspondence: dyanai@hospk.ncgm.go.jp

${ }^{1}$ Department of Internal Medicine, National Center for Global Health and Medicine Kohnodai Hospital, Chiba, Japan

Full list of author information is available at the end of the article
}

The promotion of physical activity is crucial in the management of type 2 diabetes. Systematic reviews suggest that aerobic exercise and resistance training improve glycemic control in patients with type 2 diabetes [5-9]. However, to our knowledge, there were no previous studies that investigate the association between NEAT and metabolic parameters including body mass index, waist circumference, blood pressure, glucose and lipids metabolism, in patients with type 2 diabetes.

We calculated the NEAT score with a questionnaire for evaluating physical activity habits concerned with NEAT, and studied how NEAT correlates with metabolic parameters in patients with type 2 diabetes. 


\section{Methods}

\section{Study population}

The study protocol was approved by the Medical Ethics Committee of the National Center for Global Health and Medicine (reference number NCGM-G-1151). We studied 45 subjects (22 women and 23 men) who did not take any hypoglycemic agents including metformin, and also did not take anti-hypertensive and cholesterollowering agents. Information about medical history, smoking status and medication were obtained via an interview. The subjects studied were aged between 20 and 90 years old, and were all diagnosed as having type 2 diabetes according to the Japanese diagnostic criteria for type 2 diabetes without physical disability. The clinical, biochemical and physiological characteristics of the subjects studied are shown in Table 1.

Waist circumference, blood pressure, and arterial stiffness Waist circumference was measured from the navel with the subjects breathing out while standing. Blood pressure was measured with subjects in a seated position using an automatic sphygmomanometer (HEM-762, Omron Co., Ltd, Kyoto, Japan), while arterial stiffness was examined by measuring the brachial-ankle pulse wave velocity (baPWV) using a pulse pressure analyzer (model: BP-203RPE; Nihon Colin, Tokyo, Japan).

\section{Laboratory measurements}

Plasma glucose was measured using an enzymatic method (Wako Pure Chemical Industries, Osaka, Japan). Serum insulin and hemoglobin A1c were measured by automated enzyme-linked immunosorbent assays ( $\mathrm{TOSOH}$,

Table 1 Clinical biochemical and physiological characteristics of subjects

\begin{tabular}{lc}
\hline Number of subjects & 45 \\
\hline Age (years old) & $59.9 \pm 14.5$ \\
\hline Sex (male/female) & $23 / 22$ \\
\hline Smoking (current smoker/ ex- and non-smoker & $27 / 18$ \\
\hline Body height $(\mathrm{cm})$ & $160.3 \pm 9.0$ \\
\hline Body weight $(\mathrm{kg})$ & $65.0 \pm 18.7$ \\
\hline Waist circumference $(\mathrm{cm})$ & $92.5 \pm 13.7$ \\
\hline Body mass index $\left(\mathrm{kg} / \mathrm{m}^{2}\right)$ & $26.0 \pm 5.9$ \\
\hline Systolic blood pressure $(\mathrm{mmHg})$ & $130.7 \pm 18.6$ \\
\hline Diastolic blood pressure $(\mathrm{mmHg})$ & $78.6 \pm 16.9$ \\
\hline Plasma glucose $(\mathrm{mg} / \mathrm{dl})$ & $192.3 \pm 106.4$ \\
\hline Hemoglobin A1c $(\%)$ & $8.0 \pm 2.0$ \\
\hline Serum Insulin $(\mu l U / m l$ & $18.3 \pm 20.6$ \\
\hline Serum low density lipoprotein cholesterol $(\mathrm{mg} / \mathrm{dl})$ & $130.9 \pm 31.4$ \\
\hline Serum triglyceride $(\mathrm{mg} / \mathrm{dl})$ & $181.1 \pm 95.1$ \\
\hline Serum high-density lipoprotein cholesterol $(\mathrm{mg} / \mathrm{dl})$ & $51.7 \pm 13.9$ \\
\hline Pulse wave velocity $(\mathrm{cm} / \mathrm{s})$ & $1667 \pm 417$ \\
\hline
\end{tabular}

Tokyo, Japan) and high-performance liquid chromatography $(\mathrm{TOSOH})$, respectively. Total cholesterol, triglyceride (TG), high-density lipoprotein-cholesterol (HDL-C) and low-density lipoprotein-cholesterol (LDL-C) were determined enzymatically, using commercially available kits, Tcho-l, TG-LH (Wako Pure Chemical Industries), Cholestest N HDL and Choletest LDL (Daiichi Pure Chemicals, Tokyo, Japan), respectively.

\section{Assessment of NEAT}

We asked the subjects about their habits of physical activity concerned with NEAT using an original questionnaire modified from a compendium of physical activities [10]. (See the Additional file 1). We created the NEAT score by referring to an article by Ainsworth BE and colleagues [10]. Technicians at the Clinical Research Center of the National Center for Global Health and Medicine at Kohnodai Hospital asked participants at the Outpatient Clinic about their typical habitual activities, and we also asked the subjects how high a level of exercise they engage in, including workouts in gyms, etc. Subjects who engaged in active sports-like exercise and resistance training were excluded. We evaluated each questionnaire item with a score of 1 to 3 points in order of levels of habitual physical activity and then added up the scores to determine the NEAT score.

\section{Statistical analysis}

Statistical analysis was performed using SPSS version 19 (IBM Co., Ltd, Chicago, USA). All values were expressed as the mean \pm standard deviation (SD), except for sex and smoking status. Pearson's correlation coefficient was calculated in order to analyze the association of the NEAT score with clinical, biochemical and physiological data. $P<0.05$ was considered to be statistically significant.

\section{Results}

The mean \pm SD of the NEAT score for all participants was $57.4 \pm 11.8$ (range: $37-80$ ), and $56.9 \pm 10.6$ and $57.6 \pm$ 10.1 for men and women, respectively. In all subjects studied, plasma glucose levels were not significantly associated with the NEAT score, but serum insulin levels were significantly and negatively correlated with the NEAT score (Figure 1).

In all subjects, the NEAT score was not significantly correlated with waist circumference and HDL-C levels. In women, the NEAT score was significantly and negatively correlated with waist circumference and also was significantly and positively correlated with HDL-C levels (Figure 2). In men, we could not observe a significant association between the NEAT score and waist circumference. Furthermore, and interestingly, the NEAT score in men was significantly and negatively correlated with HDL-C levels. 

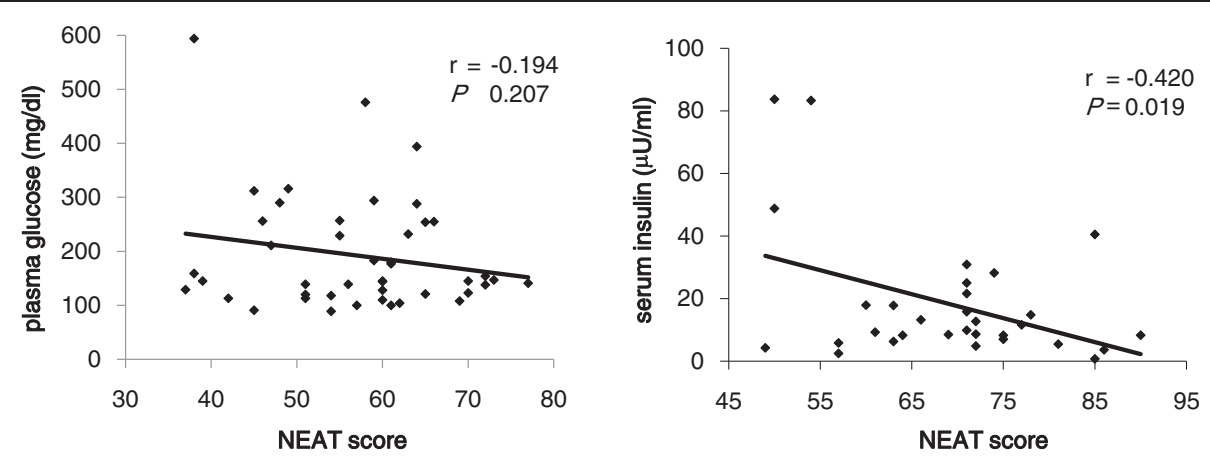

Figure 1 Correlation between the NEAT score and plasma glucose levels serum insulin levels in all subjects.

We divided subjects into two groups by waist circumference (< or $\geqq 90 \mathrm{~cm}$ for women and $<$ or $\geqq 85 \mathrm{~cm}$ for men, which is defined as abdominal obesity in the Japanese diagnostic criteria for metabolic syndrome [11]), because patients with abdominal obesity are at increased risk for CVD and hypertension [12]. In patients with abdominal obesity, the NEAT score was significantly and negatively associated with serum insulin levels (Figure 3). However, in patients without abdominal obesity, a significant association between the NEAT score and serum insulin levels was not observed.

Further, in patients with abdominal obesity, the NEAT score was significantly and negatively correlated with systolic and diastolic blood pressure (Figure 4), but in patients without abdominal obesity, we did not observe a significant association between the NEAT score and systolic and diastolic blood pressure.

Smoking has been reported to be associated with insulin resistance [13] and the development of type 2 diabetes $[13,14]$. Therefore, we divided subjects into two groups by smoking status. In current smokers, the NEAT score was significantly and negatively correlated with baPWV (Figure 5), but in ex- and non-smokers, there was no significant association between the NEAT score and PWV.

\section{Discussion}

Previous studies have suggested that the amounts of physical activity such as exercise was significantly and negatively associated with serum insulin levels $[15,16]$,
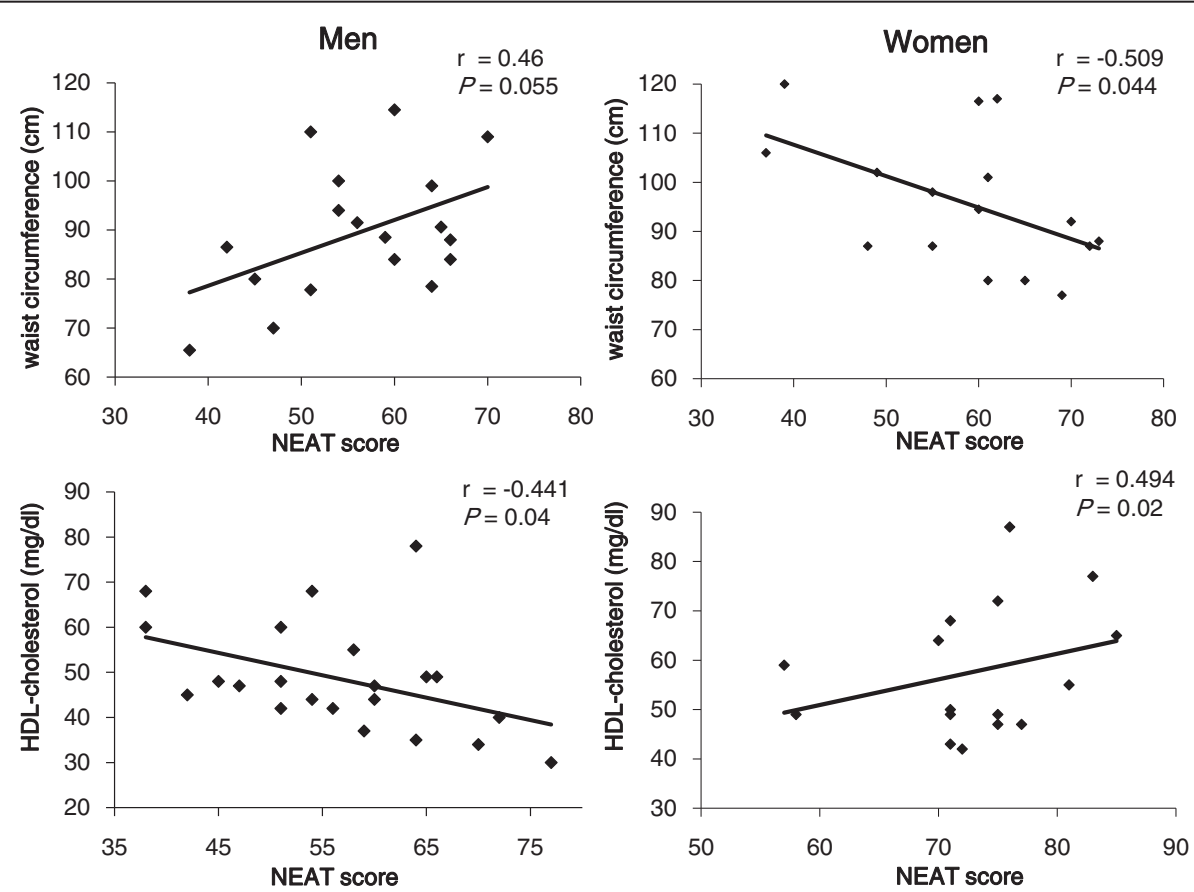

Figure 2 Correlation between the NEAT score and waist circumference and serum high-density lipoprotein (HDL)-cholesterol levels in men and women. 

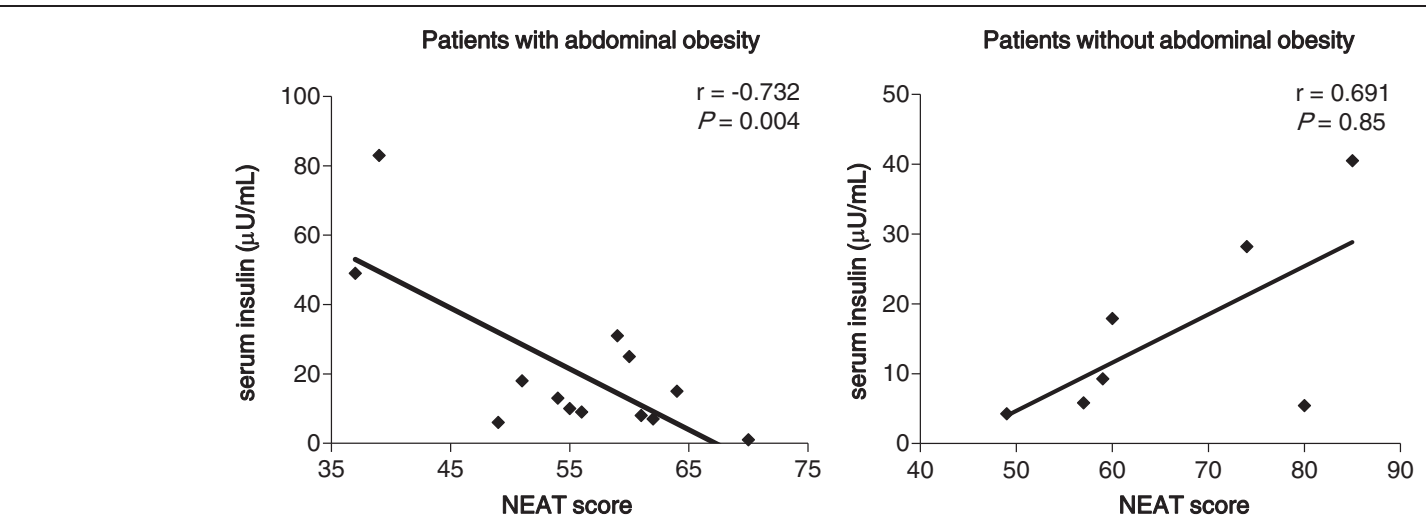

Figure 3 Correlation between the NEAT score and serum insulin levels in patients with and without abdominal obesity. Patients with abdominal obesity means male patients with waist circumference (WC) $\geqq 85 \mathrm{~cm}$ and female patients with WC $\geqq 90 \mathrm{~cm}$, and patients without abdominal obesity means male patients with $W C<85 \mathrm{~cm}$ and female patients with $W C<90 \mathrm{~cm}$.

meaning serum insulin levels were lower in active people when compared to sedentary people. In this study, the NEAT score was significantly and negatively associated with serum insulin levels, suggesting that NEAT is also associated with insulin sensitivity in addition to exercise. However, we have to mention that the correlation between NEAT and serum insulin may be largely dependent on the presence of three subjects with very high insulin and low NEAT. The NEAT score was not associated with plasma glucose levels in all participants, suggesting that the association between the NEAT score and glucose metabolism may be modest.

For all participants, the NEAT score was not correlated with waist circumference and HDL-C levels. In women with type 2 diabetes, the NEAT score was negatively associated with waist circumference and positively associated with HDL-C levels, indicating an association of NEAT with metabolic parameters in women. However, we could not observe this association in men. The study could not explain why this association of NEAT

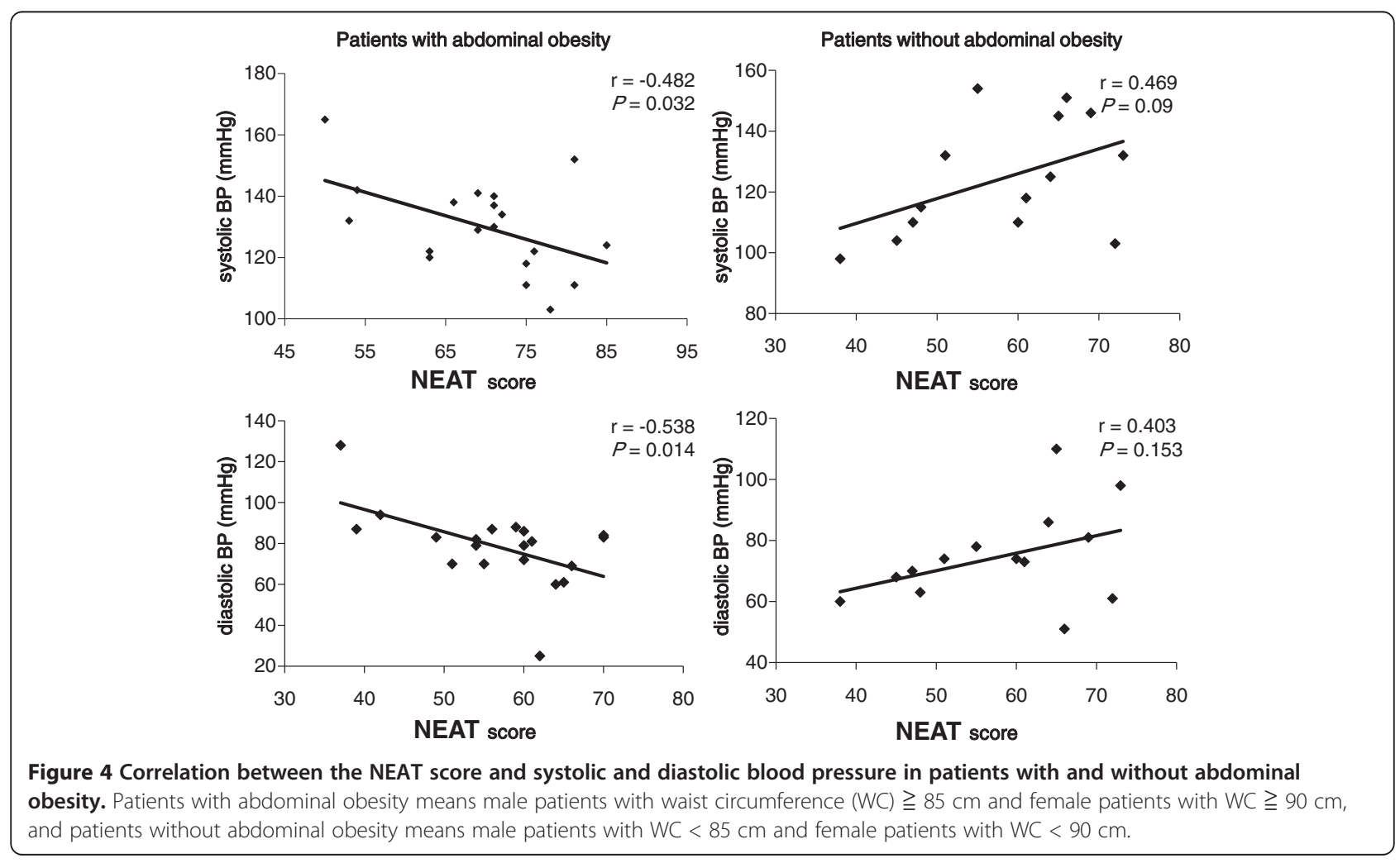



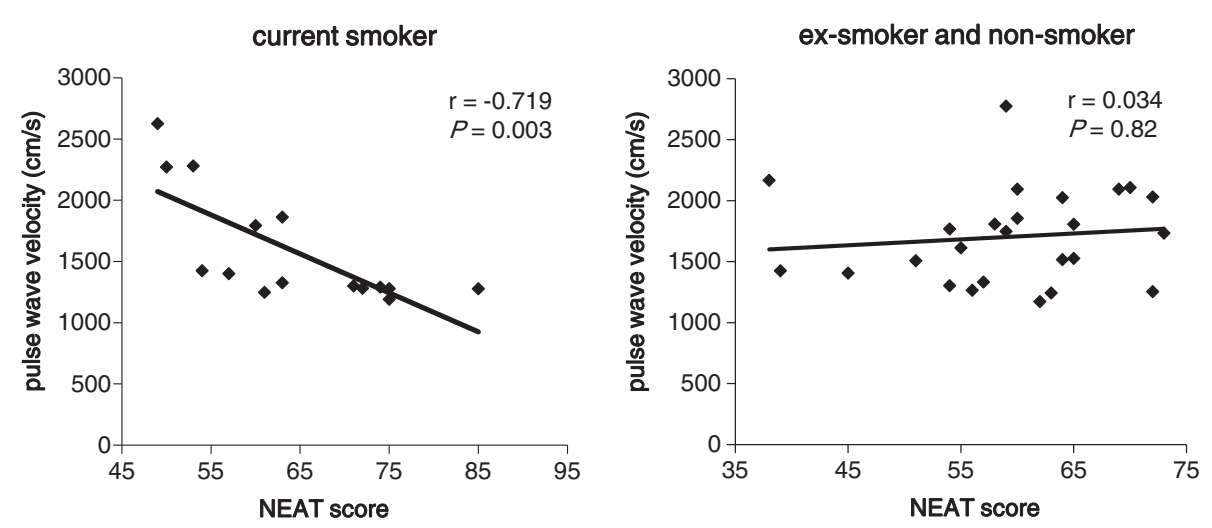

Figure 5 Correlation between the NEAT score and pulse wave velocity in current smokers and ex- and non-smokers.

score to waist circumference and HDL-C in women was different from that in men, and we would have to perform further studies with a greater number of participants to explain the association of NEAT with waist circumference and HDL-C.

The metabolic syndrome, which is characterized by abdominal obesity, high TG, low HDL-C, elevated blood pressure, glucose intolerance and insulin resistance, has been identified as a clustering of risk factors for atherosclerotic diseases [17]. Insulin resistance has been reported to be significantly associated with abdominal obesity [17], and accumulated abdominal fat induces insulin resistance with the secretion of various cytokines and the reduced secretion of adiponectin $[18,19]$. The previous study showed that obese patients with both type 2 diabetes and hypertension had a significantly lower likelihood of adopting physical activity to control their weight than those with neither condition $(6 \%$ versus $12 \%, P<0.01$ ) [20], suggesting that NEAT is more crucial for controlling body weight in obese patients with diabetes compared with those without diabetes. Our study showed that in patients with abdominal obesity, the NEAT score was negatively correlated with serum insulin levels, suggesting that NEAT is associated with insulin resistance in type 2 diabetic patients with abdominal obesity. NEAT has been reported to play an important role in controlling body weight in patients with obesity $[21,22]$, which is supported by our result. To our knowledge, this is the first study to report that NEAT is associated with insulin sensitivity in patients with type 2 diabetes.

Insulin resistance and/or abdominal obesity induce elevation of blood pressure due to sodium retention, sympathetic over-activity, vasoconstriction and activation of the renin-angiotensin system [18]. Regular exercise training has been reported to induce a moderate antihypertensive effect and aerobic exercise has been also reported to lower blood pressure among obese subjects $[23,24]$. However, the association of NEAT with blood pressure remains to be elucidated. In this study, although a significant association between blood pressure and the NEAT score was not found in patients without abdominal obesity, the NEAT score was significantly and negatively correlated with both systolic and diastolic blood pressure in patients with abdominal obesity. These results suggest that NEAT may be associated with reduction of blood pressure in type 2 diabetic patients with abdominal obesity.

Smoking is a crucial risk factor for atherosclerotic diseases $[14,25,26]$. Smoking has been reported to accelerate atherosclerosis due to impairment of the platelet and vascular endothelial functions, oxidative stress, and induction of serum lipids abnormalities [27]. Smoking is associated with elevation of TC and TG and reduction of HDL-C levels [28,29]. In this study, serum HDL-C levels (mean $\pm \mathrm{SD} ; 45.1 \pm 10.1 \mathrm{mg} / \mathrm{dl}$ ) in smokers were significantly lower than those $(55.9 \pm 14.5 \mathrm{mg} / \mathrm{dl})$ in exand non-smokers $(P=0.01$ with a Mann-Whitney $U$ test). In our study, the NEAT score was significantly and negatively correlated with baPWV as the clinical marker for atherosclerosis in current smokers. Physical activity has been reported to improve the vascular endothelial function [30,31] and reduce oxidative stress and lowgrade inflammation [32], which may partially explain a negative correlation between the NEAT score and baPWV. However, it remains unknown why this association between the NEAT score and PWV was not found in ex- and non-smokers, which requires further study. To our knowledge, this is the first report to show that NEAT is associated with an improvement in the atherosclerotic marker in current smokers with type 2 diabetes.

Limitations of the study need to be addressed. This is a cross-sectional study, limiting inferences of causality and its direction. There are some confounding factors to adjust such as dietary intake, social status, and other life habits. The NEAT score calculated with the questionnaire 
is subjective data and may not always represent the true NEAT $[33,34]$. The possibility of recall bias cannot be denied. To determine the exact NEAT score is difficult and complicated, but it is important to evaluate actual physical activity in daily lives rather than in laboratories [35,36]. The validity of methods for measuring NEAT is still controversial, however, we believe that a questionnaire is one of the most useful and reliable methods of measuring NEAT. We should mention further limitations on our approach, including the small sample size and the reliability of self reported activities. The primary drawback of the study was that a questionnaire was used rather than objective measures. A third factor could easily explain both the status of health and the physical activity levels. It could be that a third factor (for example, genetics, or aerobic capacity) underlies both the increased NEAT and the health variables measured [37-43], and that NEAT itself did not improve metabolic parameters. According to the Organization for Economic Co-operation and Development (OECD) Health Data 2012, Japan has a markedly lower obesity rate than most other countries. Our results may not be consistently observed in other countries. Further studies, preferably with larger numbers of subjects, will be needed in the future.

\section{Conclusions}

In conclusion, this study demonstrated that NEAT is associated with amelioration of insulin sensitivity in all participants, and reduction of waist circumference and elevation in HDL-C in women with type 2 diabetes, and is also to improvement in insulin resistance and blood pressure in diabetic patients with abdominal obesity. Furthermore, our study demonstrated that NEAT is associated with amelioration in PWV as the clinical marker for atherosclerosis in current smokers with type 2 diabetes.

\section{Additional file}

Additional file 1: Non-Exercise Activity Thermogenesis (NEAT)

score.

\section{Competing interests}

The authors declare that they have no competing interests.

\section{Authors' contributions}

All eight authors have substantially contributed to conception and design, acquisition of data or analysis and interpretation of data; drafting the article or revising it critically for important intellectual content; and all authors read and approved the final manuscript.

\section{Acknowledgments}

This study was supported by a grant from the National Center for Global Health and Medicine (22-120). The authors would like to thank Tomoko Kaga, Yukari Takano, Fumi Kawasaki, Yukie Kawamura, and Naomi Inoue at Clinical Research Center, National Center for Global Health and Medicine Kohnodai Hospital, for their technical help.

\section{Author details}

'Department of Internal Medicine, National Center for Global Health and Medicine Kohnodai Hospital, Chiba, Japan. ${ }^{2}$ General Internal Medicine Community Healthcare Studies, Jichi Medical University Graduate School, Tochigi, Japan. ${ }^{3}$ Department of Diabetes and Metabolic Medicine, Center Hospital, National Center for Global Health and Medicine, Tokyo, Japan. ${ }^{4}$ First Department of Comprehensive Medicine, Saitama Medical Center, Jichi Medical University School of Medicine, Saitama, Japan. ${ }^{5}$ Department of Human Health and Design, Faculty of Human Life and Environmental Sciences, Showa Women's University, Tokyo, Japan. ${ }^{6}$ Department of Diabetes Research, Diabetes Research Center, National, Center for Global Health and Medicine, Tokyo, Japan.

Received: 27 March 2013 Accepted: 15 May 2013

Published: 27 May 2013

\section{References}

1. Levine JA: Non-exercise activity thermogenesis (NEAT). Nutr Rev 2004, 62:S82-S97.

2. Zhang L, Qin LQ, Cui HY, Liu AP, Wang PY: Prevalence of cardiovascular risk factors clustering among suburban residents in Beijing, China. Int J Cardiol 2011, 151:46-49.

3. Singh RB, Ghosh S, Niaz AM, Gupta S, Bishnoi I, Sharma JP, Agarwal P, Rastogi SS, Beegum R, Chibo H, et al: Epidemiologic study of diet and coronary risk factors in relation to central obesity and insulin levels in rural and urban populations of north India. Int J Cardiol 1995, 47:245-255.

4. Thompson PD, Buchner D, Pina IL, Balady GJ, Williams MA, Marcus BH, Berra K, Blair SN, Costa F, Franklin B, Fletcher GF, Gordon NF, Pate RR, Rodriguez BL, Yancey AK, Wenger NK, American Heart Association Council on Clinical Cardiology Subcommittee on Exercise, Rehabilitaion, and Prevention, American Heart Association Council on Nutrition, Physical Activity, and Metabolism Subcommittee on Physical Activity: Exercise and physical activity in the prevention and treatment of atherosclerotic cardiovascular disease: a statement from the Council on Clinical Cardiology (Subcommittee on Exercise, Rehabilitaion, and Prevention) and the Council on Nutrition, Physical Activity, and Metabolism (Subcommittee on Physical Activity). Circulation 2003, 107:3109-3116.

5. Boulé NG, Haddad E, Kenny GP, Wells GA, Sigal RJ: Effects of exercise on glycemic control and body mass in type 2 diabetes mellitus: a metaanalysis of controlled clinical trials. JAMA 2001, 286:1218-1227.

6. Eves ND, Plotnikoff RC: Resistance training and type 2 diabetes: Considerations for implementation at the population level. Diabetes Care 2006, 29:1933-1941.

7. Snowling NJ, Hopkins WG: Effects of different modes of exercise training on glucose control and risk factors for complications in type 2 diabetic patients: a meta-analysis. Diabetes Care 2006, 29:2518-2527.

8. Thomas DE, Elliott EJ, Naughton GA: Exercise for type 2 diabetes mellitus. Cochrane Database Syst Rev 2006, 3, CD002968.

9. Sigal RJ, Kenny GP, Boulé NG, Wells GA, Prud'homme D, Fortier M, Reid RD, Tulloch H, Coyle D, Phillips P, Jennings A, Jaffey J: Effects of aerobic training, resistance training, or both on glycemic control in type 2 diabetes. Ann Intern Med 2007, 147:357-369

10. Ainsworth BE, Haskell WL, Herrmann SD, Meckes N, Bassett DR Jr, TudorLocke C, Greer JL, Vezina J, Whitt-Glover MC, Leon AS: Compendiumu of physical activities: a second update of codes and MET values. Med Sci Sports Exerc 2011, 2011(43):1575-1581.

11. Examination Committee of Criteria for 'Obesity Disease' in Japan; Japan Society for the Study of Obesity: New criteria for 'obesity disease' in Japan. Circ J 2002, 66:987-992.

12. Janssen I, Katzmarzyk PT, Ross R: Body mass index, waist circumference, and health risk: evidence in support of current National Institute of Health guidelines. Arch Intern Med 2002, 162:2074-2079.

13. Facchini FS, Hollenbeck CB, Jeppesen JJ, Chen Y-DI, Reaven GM: Insulin resistance and cigarette smoking. Lancet 1992, 339:1128-1130.

14. Tenenbaum A, Fisman EZ, Adler Y, Motro M, Boyko V, Behar S: Smoking and development of type 2 diabetes in patients with decreased functional capacity. Int J Cardiol 2005, 104:275-281.

15. Golbidi S, Mesdaghinia A, Laher I: Exercise in the Metabolic Syndrome. Oxid Med Cell Longev 2012, 2012:349710.

16. Seals DR, Walker AE, Pierce GL, Lesniewski LA: Habitual exercise and vascular aging. J Physiol 2009, 587:5541-5549. 
17. Reaven GM: Insulin resistance: the link between obesity and cardiovascular disease. Med Clin North Am 2011, 95:875-892.

18. Yanai $H$, Tomono $Y$, Ito $K$, Furutani $N$, Yoshida $H$, Tada N: The underlying mechanisms for development of hypertension in the metabolic syndrome. Nutr J 2008, 7:10.

19. Ziemke F, Mantzoros CS: Adiponectin in insulin resistance: lessons from translational research. Am J Clin Nutr 2010, 91:258S-261S.

20. Zhao G, Ford ES, Li C, Mokdad AH: Weight control behaviors in overweight/obese U.S. adults with diagnosed hypertension and diabetes. Cardiovasc Diabeto/ 2009, 8:13.

21. Physiology RE: A NEAT way to control weight? Science 2005, 307:530-531.

22. Levine JA, Lanningham-Foster LM, McCrady SK, Krizan AC, Olson LR, Kane $\mathrm{PH}$, Jensen MD, Clark MM: Interindividual variation in posture allocation: possible role in human obesity. Science 2005, 307:584-586.

23. Eriksson J, Taimela S, Koivisto VA: Exercise and the metabolic syndrome. Diabetologia 1997, 40:125-135.

24. Miller ER 3rd, Erlinger TP, Young DR, Jehn M, Charleston J, Rhodes D, Wasan SK, Appel LJ: Results of the Diet, Exercise, and Weight Loss Intervention Trial (DEW-IT). Hypertension 2002, 40:612-618.

25. Wolf PA, D'Agostino RB, Kannel WB, Bonita R, Belanger AJ: Cigarette smoking as a risk factor for stroke: The Framingham Study. JAMA 1988, 259:1025-1029.

26. Yano K, Reed DM, McGee DL: Ten-year incidence of coronary heart disease in the Honolulu Heart Program: relationship to biologic and lifestyle characteristics. Am J Epidemiol 1984, 119:653-666.

27. Vogel RA: Coronary risk factors, endothelial function, and atherosclerosis: a review. Clin Cardiol 1997, 20:426-432.

28. Chelland Campbell S, Moffatt RJ, Stamford BA: Smoking and smoking cessation - the relationship between cardiovascular disease and lipoprotein metabolism: a review. Atherosclerosis 2008, 201:225-235.

29. Craig WY, Palomaki GE, Haddow JE: Cigarette smoking and serum lipid and lipoprotein concentrations: an analysis of published data. BMJ 1989 298:784-788.

30. Lenk K, Uhlemann M, Schuler G, Adams V: Role of endothelial progenitor cells in the beneficial effects of physical exercise on atherosclerosis and coronary artery disease. J App Physiol 2011, 111:321-328.

31. Metsios GS, Stavropoulos-Kalinoglou A, Sandoo A, van Zanten JJ, Toms TE, John H, Kitas GD: Vascular function and inflammation in rheumatoid arthritis: the role of physical activity. Open Cardiovasc Med J 2010, 4:89-96.

32. Teixeira-Lemos E, Nunes S, Teixeira F, Reis F: Regular physical exercise training assists in preventing type 2 diabetes development: focus on its antioxidant and anti-inflammatory properties. Cardiovasc Diabetol 2011, $10: 12$.

33. Colbert LH, Matthews CE, Havighurst TC, Kim K, Schoeller DA: Comparative validity of physical activity measures in older adults. Med Sci Sports Exerc 2011, 43:867-876.

34. Colbert LH, Schoeller DA: Expending our physical activity (measurement) budget wisely. J App/ Physiol 2011, 111:606-607.

35. Levine JA, Vander Weg MW, Hill JO, Klesges RC: Non-exercise activity thermogenesis: the crouching tiger hidden dragon of societal weight gain. Arterioscler Thromb Vasc Biol 2006, 26:729-736.

36. Snitker S, Tataranni PA, Ravussin E: Spontaneous physical activity in a respiratory chamber is correlated to habitual physical activity. Int J Obes Relat Metab Disord 2001, 25:1481-1486.

37. Luke A, Durazo-Arvizu RA, Rotimi CN, lams H, Schoeller DA, Adeyemo AA, Forrester TE, Wilks R, Cooper RS: Activity energy expenditure and adiposity among black adults in Nigeria and the United States. Am J Clin Nutr 2002, 75:1045-1050.

38. Luke A, Durazo-Arvizu RA, Cao G, Forrester TE, Wilks RJ, Schoeller DA, Cooper RS: Activity, adiposity and weight change in Jamaican adults. West Indian Med J 2007, 56:398-403

39. Dugas LR, Ebersole K, Schoeller D, Yanovski JA, Barquera S, Rivera J, Durazo-Arzivu R, Luke A: Very low levels of energy expenditure among pre-adolescent Mexican-American girls. Int J Pediatr Obes 2008, 3:123-126.

40. Racette SB, Schoeller DA, Kushner RF, Neil KM, Herling-laffaldano K: Effects of aerobic exercise and dietary carbohydrate on energy expenditure and body composition during weight reduction in obese women. Am J Clin Nutr 1995, 61:486-494.

41. Manini TM, Patel KV, Bauer DC, Ziv E, Schoeller DA, Mackey DC, Li R, Newman AB, Nalls M, Zmuda JM, Harris TB: Health, Aging and Body
Composition Study. European ancestry and resting metabolic rate in older African Americans. Eur J Clin Nutr 2011, 65:663-667.

42. Schulz LO, Schoeller DA: A compilation of total daily energy expenditures and body weights in healthy adults. Am J Clin Nutr 1994, 60:676-681.

43. Jones PJ, Schoeller DA: Polyunsaturated:saturated ratio of diet fat influences energy substrate utilization in the human. Metabolism 1988 $37: 145-151$

doi:10.1186/1758-5996-5-26

Cite this article as: Hamasaki et al.: Correlations of non-exercise activity thermogenesis to metabolic parameters in Japanese patients with type 2 diabetes. Diabetology \& Metabolic Syndrome 2013 5:26.

\section{Submit your next manuscript to BioMed Central and take full advantage of:}

- Convenient online submission

- Thorough peer review

- No space constraints or color figure charges

- Immediate publication on acceptance

- Inclusion in PubMed, CAS, Scopus and Google Scholar

- Research which is freely available for redistribution

Submit your manuscript at www.biomedcentral.com/submit
C Biomed Central 